\section{SAT0377 DIFFERENCES IN CLINICAL CHARACTERISTICS, QUALITY OF LIFE, DISABILITY, AND WORK PRODUCTIVITY IN PSORIATIC ARTHRITIS PATIENTS BY GENDER: FINDINGS FROM A CROSS-SECTIONAL SURVEY IN THE US AND EUROPE}

Laure Gossec ${ }^{1}$, Jessica A. Walsh ${ }^{2}$, Kaleb Michaud ${ }^{3}$, Steve Peterson ${ }^{4}$ Elizabeth Holdsworth ${ }^{5}$, Chetan Karyekar ${ }^{4}$, Nicola Booth ${ }^{5}$, Jessalyn Kemp ${ }^{5}$, Soumya D. Chakravarty ${ }^{6,7}$, Shelly Kafka ${ }^{6}$, Alexis Ogdie ${ }^{8} .{ }^{1}$ Sorbonne Universite, Paris, France; ${ }^{2}$ University of Utah, Salt Lake City, UT, United States of America; ${ }^{3}$ University of Nebraska Medical Center, Omaha, NE, United States of America; ${ }^{4}$ Janssen Global Services, LLC, Horsham, PA, United States of America; ${ }^{5}$ Adelphi Real World, Manchester, United Kingdom; ' 6 Janssen Scientific Affairs, LLC, Horsham, PA, United States of America; ${ }^{7}$ Drexel University College of Medicine, Philadelphia, PA, United States of America; ${ }^{8}$ Perelman School of Medicine, University of Pennsylvania, Philadelphia, PA, United States of America

Background: Psoriatic arthritis (PsA) prevalence is equal in men and women, though gender may play a role in driving mechanisms of PsA leading to differences in manifestations of clinical disease (1).

Objectives: Assess key differences in clinical characteristics, disability, quality of life, and work productivity by gender in real-world practice.

Methods: Cross-sectional survey of rheumatologists and dermatologists and their patients in France, Germany, Italy, Spain, UK, and US. Data were collected from Jun-Aug 2018 via physician-completed patient record forms and patient self-completed forms. Data were analyzed by gender. Demographic characteristics, treatment use, and clinical characteristics (Tender Joint Count [TJC], Swollen Joint Count [SJC], Body Surface Area $[B S A]$ psoriasis) were reported by physicians, while quality of life (EQ5D and PsAID12), disability (HAQ-DI), and work productivity (WPAI) were reported by patients. Men and women were compared using parametric tests and non-parametric tests where appropriate.

Results: Data were collected for 2270 patients (595 US, 1675 Europe). Demographic characteristics, time from first symptoms to diagnosis, biologic treatment, and clinical characteristics were comparable between women and men (Table 1). More women reported worse quality of life,

Table 1. Demographic and clinical characteristics in women and men [mean (SD) or $n(\%)]$

\begin{tabular}{lccc}
\hline & Women & Men & P value \\
\hline $\mathrm{n}(\%)$ & $1047(46.1)$ & $1223(53.9)$ & - \\
Age, years & $48.3(13.7)$ & $48.8(12.8)$ & 0.42 \\
Working full time ${ }^{\star}, \mathrm{n}(\%)$ & $206(49.4)$ & $350(68.6)$ & $<0.01$ \\
Charlson Comorbidity Index score & $1.10(0.51)$ & $1.15(0.58)$ & $<0.01$ \\
Time from first symptoms to diagnosis, & $1.48(3.53) 4.87$ & $1.14(2.48) 4.95$ & 0.76 \\
years & $(6.15)$ & $(5.79)$ & 0.42 \\
PsA duration, years & & & \\
Currently receiving biologic treatment, & $557(53.2)$ & $674(55.1)$ & 0.38 \\
$\mathrm{n}(\%)$ & & & \\
BSA psoriasis involvement, mean\% & $5.5(8.4)$ & $5.5(8.1)$ & 0.87 \\
Swollen Joint Count & $3.2(7.0)$ & $3.5(6.9)$ & 0.39 \\
Tender Joint Count & $4.1(5.2)$ & $4.5(8.0)$ & 0.03 \\
Enthesitis, $\mathrm{n}(\%)$ & $59(5.6)$ & $72(5.9)$ & 0.86 \\
Dactylitis, $\mathrm{n}(\%)$ & $79(7.5)$ & $75(6.1)$ & 0.21 \\
\hline${ }^{*}$ Outside the home & & &
\end{tabular}

disability, and work activity impairment than men (Table 2).

Table 2. Quality of life, disability, and work productivity in women and men [mean (SD)]

\begin{tabular}{lccc}
\hline & Women & Men & P value \\
\hline EQ5D utility score & $0.80(0.18)$ & $0.82(0.17)$ & 0.02 \\
HAQ-DI score & $0.56(0.60)$ & $0.41(0.52)$ & $<0.01$ \\
PSAID12 score & $2.66(2.07)$ & $2.27(1.98)$ & $<0.01$ \\
WPAI percentage of activity & $27.9(22.0) 4.0$ & $24.6(22.4) 5.8$ & $<0.01$ \\
impairment & $(14.0)$ & $(19.2)$ & 0.62 \\
WPAl percentage of work time & & & \\
missed & & & \\
\hline
\end{tabular}

Conclusion: In women and men with similar PsA disease activity and treatment rates, women experienced worse quality of life, greater disability, and greater work impairment, despite a lower burden of comorbidities.

\section{REFERENCE}

[1] Billi AC, Kahlenberg JM, Gudjonsson JE. Sex bias in autoimmunity. Curr Opin Rheumatol. 2019 Jan;31(1):53-61.
Disclosure of Interests: Laure Gossec Grant/research support from: AbbVie, BMS, Celgene, Janssen, Lilly, MSD, Novartis-Sandoz, Pfizer, Sanofi, and UCB, Consultant for: AbbVie, Biogen, BMS, Celgene, Janssen, Lilly, MSD, Nordic Pharma, Novartis-Sandoz, Pfizer, Roche, Sanofi, and UCB Consultant for: $L$ Gossec has received honoraria from Celgene as investigator for this study, Jessica A. Walsh Grant/research support from: Abbvie, Pfizer, Consultant for: Abbvie, Celgene, Lilly, Novartis, Kaleb Michaud Grant/research support from: Pfizer (within past 2 years), Steve Peterson Shareholder of: Janssen, Employee of: BMS (2000-2002), Janssen (2002 present), Elizabeth Holdsworth Employee of: Adelphi Real World, Chetan Karyekar Shareholder of: J\&J, Employee of: Janssen Scientific Affairs, LLC, Abbott, BMS, Novartis, Nicola Booth Employee of: Adelphi Real World, Jessalyn Kemp Employee of: Adelphi Real World, Soumya D Chakravarty Shareholder of: Johnson \& Johnson, Employee of: Johnson \& Johnson, Shelly Kafka Shareholder of: J\&J, Employee of: J\&J, Alexis Ogdie Grant/research support from: (To my university) Novartis, Pfizer, Grant/research support from: Novartis, Pfizer, Grant/research support from: Novartis, Pfizer, Grant/research support from: Novartis, Pfizer, Consultant for: AbbVie, Bristol-Myers Squibb, Celgene, Corrona, Eli Lilly and Com pany, Novartis, Pfizer, and Takeda, Consultant for: AbbVie, Amgen, Bristol-Myers Squibb, Celgene, Corrona, Eli Lilly, Novartis, Pfizer Inc, Takeda, Consultant for: Abbvie, Amgen, BMS, Celgene, Corrona, Lilly, Novartis, Pfizer, Takeda, Consultant for: Abbvie, Amgen, BMS, Celgene, Corrona Lilly, Novartis, Pfizer, Takeda

DOI: 10.1136/annrheumdis-2019-eular.7370

\section{SAT0378 DRIVERSOF DISCORDANCE IN PSORIATIC ARTHRITIS WHEN ANALYZING THE LINK BETWEEN PATIENT- PERCEIVED GOOD STATUS AND THE DISEASE ACTIVITY IN PSORIATIC ARTHRITIS (DAPSA) COMPOSITE SCORE: AN ANALYSIS OF 436 PATIENTS FROM THE INTERNATIONAL REFLAP OBSERVATIONAL STUDY}

Laure Gossec, Maarten de Wit, Laura C. Coates, Umut Kalyoncu,

Emmanuelle Dernis, Adeline Ruyssen-Witrand, Ying Ying Leung, Rossana Scrivo, Juan D. Cañete, Penelope Palominos, Sandra Tälli, Uta Kiltz, Martin Soubrier, Lihi Eder, Ana-Maria Orbai, Josef S. Smolen. RFIP study group, PARIS, France

Background: In Psoriatic arthritis (PsA), the objective of treatment is remission or low disease which can be defined using the Disease Activity in PSoriatic Arthritis (DAPSA) (ref1). We previously showed DAPSA was associated to patient-perceived good status (i.e., self-assessed remission or low disease, yes/no) (ref2). However, some discordance was noted between patient-perceived status and the composite score. This discordance may be linked to demographic elements (such as age, gender or country), disease activity components (such as skin involvement which is not assessed in DAPSA) or patient-reported outcomes (such as fatigue or depressive affects). A better understanding of this discordance would be helpful in the context of shared decision-making.

Objectives: To explore the drivers of discordance between patient-perceived remission or low disease and DAPSA-defined remission or low disease.

Methods: This is an analysis of the first visit of ReFlap (NCT03119805 ref2), an observational study in 14 countries of consecutive adult patients with definite PsA $>2$ years of disease duration. Discordance in assessment of remission/low disease status was defined as a disagreement between a specific patient question (are you in remission or low disease, yes/no) and DAPSA-defined remission/low disease (i.e., score $<=14$, yes/ no). Potential drivers of this discordance were analysed through univariable then stepwise multivariable logistic regression. Variables analysed were demographic (age, gender, disease duration, gross domestic product of country of origin), disease-related (joint counts, psoriasis BSA, enthesitis, CRP) and patient-reported outcomes (pain, fatigue, depressive affect and anxiety). There was no imputation of missing data.

Results: Among 436 patients, mean age 52.3 (SD 12.5) years, mean disease duration 10.1 (8.1) years, $218(50.8 \%)$ male; 259 (63.5\%) were taking a conventional DMARD and $247(60.5 \%)$ a biologic. Disease activity was moderate: $36.1 \%$ had no current psoriasis skin lesions and mean swollen joint count was 2.2 (7.1). Remission or low disease was frequent both using the patient question ( $\mathrm{N}=286,65.6 \%)$ and using DAPSA $(\mathrm{N}=246,56.4 \%)$. Discordance between patient-reported status and DAPSA 